\title{
Preovulatory secretion of gonadotrophins and TSH in cyclic rats with small lesions in the preoptic area
}

\author{
R. G. Dyer, M. B. ter Haar* and D. Saphier $\dagger$ \\ A.R.C. Institute of Animal Physiology, Babraham, Cambridge CB2 4AT, U.K.
}

\begin{abstract}
Summary. Animals with unilateral or bilateral lesions, with respectively 85 and $70 \%$ of intact preoptic area tissue remaining, returned to regular oestrous cycles. By comparison with sham-operated controls, rats with lesions had more days with a leucocytic smear in each of the 1 st, 2 nd or 3 rd post-operative cycle, before returning to a 4-day cycle. Hormone measurements of blood collected during the afternoon of pro-oestrus showed that, in rats with bilateral lesions, the duration of the preovulatory LH secretion was significantly shortened, although peak levels were unchanged; the initial phase of the preovulatory FSH secretion was lost; and much of the prolactin surge was also inhibited. The TSH surge was unaffected.
\end{abstract}

\section{Introduction}

In the female rat the plasma concentrations of $\mathrm{LH}, \mathrm{TSH}$ and prolactin increase during the afternoon of pro-oestrus to reach maximal levels at about 19:00 h (Brown-Grant \& Greig, 1975; Brown-Grant, Dutton \& ter Haar, 1977). During this period FSH levels also increase, but peak values are not achieved until later, at about $03: 00 \mathrm{~h}$ on the day of oestrus. It is well established that the preovulatory increases in plasma gonadotrophin concentrations are controlled from the hypothalamus, and in particular the preoptic area (Gorski, 1966). This part of the forebrain was long considered essential for the maintenance of cyclic ovulation in rats, but it is now known than even when large areas of the medial preoptic area are destroyed, the rats still ovulate regularly. Clemens, Smalstig \& Sawyer (1976) showed that the effect of such lesions in rats with regular 4-day cycles was to induce an ovarian cycle which lasted for about 15 days: each ovulation appeared to be followed by a prolonged dioestrous phase.

The amount of $\mathrm{LH}$ released before ovulation is substantially in excess of the amount required to luteinize the granulosa cells of the mature follicle (Greig \& Weisz, 1973). The occurrence of ovulation only indicates, therefore, that the amount of $\mathrm{LH}$ released has been above the threshold required for luteinization. The present study was designed to establish whether preoptic lesions which still permitted regular ovulation (a) altered the amount of preovulatory $\mathrm{LH}$ secreted by the cyclic female rat, and (b) modified the normal pro-oestrous afternoon/evening profile of plasma FSH, TSH and prolactin.

\section{Materials and Methods}

The 99 rats used were kept in a standard controlled environment with artificial lighting provided for $14 \mathrm{~h}$ from $05: 00 \mathrm{~h}$ each day. The occurrence of regular 4-day oestrous cycles in all rats was confirmed for at least 2 cycles by daily vaginal smears. With the aid of a Grass radiofrequency lesion maker set to deliver $7.5 \mathrm{~mA}$ for $60 \mathrm{sec}$, unilateral preoptic lesions were made in 27 of the rats, and bilateral lesions in a further 47 animals. The lesions were placed $6.8 \mathrm{~mm}$ rostral to the interaural line, $0.8 \mathrm{~mm}$ from the midline, and at a depth of $7.0 \mathrm{~mm}$ from the surface of the cerebral cortex (König \& Klippel, 1963). The remaining 25 rats served as controls which were subjected to the same preparatory treatment as

* Present address: Elsevier/North-Holland Biomedical Press, 14A Regent Street, Cambridge CB2 IDB, U.K.

$\uparrow$ Present address: Department of Zoology, University College of North Wales, Bangor, Gwynedd. 
the experimental animals, but without insertion of the electrodes into the brain. Subsequent histology showed that each lesion, including damage caused by the electrode tract, destroyed about $30 \%$ of the preoptic area on one side, and that the suprachiasmatic nuclei remained intact. The lesions were made on the afternoon of pro-oestrus: vaginal smears were taken daily thereafter. Between 14 and 28 days after treatment (see Table 1) the animals were killed quickly by decapitation at 16:00, 17:30, 19:00, $20: 30$ or $22: 00 \mathrm{~h}$ on the day of a pro-oestrous vaginal smear, and trunk blood was collected.

Plasma was separated, stored frozen at $-20^{\circ} \mathrm{C}$, and subsequently submitted to radioimmunoassay procedures for estimation of LH, FSH, TSH and prolactin with the kits provided by NIAMDD (Brown-Grant \& ter Haar, 1977). The antisera used were respectively ARLH-S3, AFRSH-S6, ARTSH-S3 and ARP-S3, which provided a sensitivity of 7.5, 78, 50 and 10 ng equivalents of the respective NIAMDD-RP1 preparation. For plasma pools with low concentrations of hormone the intra-assay coefficients of variation were $11,11,9$ and $27 \%$ and the inter-assay coefficients of variation were $32,29,16$ and $37 \%$, while for high concentrations of hormone the respective coefficients of variation were $6,6,4$ and $15 \%$ and $25,17,17$ and $18 \%$ for $\mathrm{LH}, \mathrm{FSH}, \mathrm{TSH}$ and prolactin respectively.

Student's two-tailed $t$ test was used to compare hormone levels in the various groups.

\section{Results}

Six of the animals with bilateral preoptic lesions showed a persistently cornified vaginal smear, and these animals were excluded from the data analysed.

Characteristic alterations in the cell patterns in the vaginal smears indicated that ovulation soon occurred regularly again in the remaining 93 rats. After operation, the cycle length was longer overall in the lesioned animals than in the controls (Table 1), but after two cycles with more than 2 days of leucocytic smears, most animals resumed 4-day cyclicity (Table 2). There were no significant differences for the values at the different times of blood collection in Table 2, and therefore the groups used for the hormonal data (Text-fig. 1) were considered to be homogeneous.

Table 1. Time between surgery and death, and the number of days on which the vaginal smear showed cornified cells (oestrus) or contained leucocytes (dioestrus)

\begin{tabular}{lcccc}
\hline \multicolumn{1}{c}{ Treatment } & $\begin{array}{c}\text { No. of } \\
\text { rats }\end{array}$ & $\begin{array}{c}\text { Before } \\
\text { death }\end{array}$ & $\begin{array}{l}\text { Of oestrous } \\
\text { smears }(\%)\end{array}$ & $\begin{array}{c}\text { Of dioestrous } \\
\text { smears (\%) }\end{array}$ \\
\hline Sham-operated controls & 25 & $18 \cdot 4 \pm 4 \cdot 2$ & $5 \cdot 2 \pm 1 \cdot 8(28)$ & $9 \cdot 2 \pm 3 \cdot 0(50)$ \\
Unilateral preoptic lesions & 27 & $21 \cdot 1 \pm 2 \cdot 8$ & $5 \cdot 2 \pm 1 \cdot 3(25)$ & $11 \cdot 3 \pm 2 \cdot 2(54)$ \\
Bilateral preoptic lesions & 47 & $24 \cdot 1 \pm 4 \cdot 7$ & $4 \cdot 9 \pm 2 \cdot 4(20)$ & $15 \cdot 2 \pm 4 \cdot 4(63)$ \\
\hline
\end{tabular}

Table 2. Effects of bilateral preoptic lesions upon the next two ovarian cycles (expressed as mean no. of days ( \pm s.d.) on which leucocytes appeared in the vaginal smears) for rats eventually killed at different times on the afternoon of pro-oestrus

\begin{tabular}{|c|c|c|c|c|c|}
\hline & \multicolumn{5}{|c|}{ Time of blood collection (h) } \\
\hline & $16: 00$ & $17: 30$ & $19: 00$ & $20: 30$ & $22: 00$ \\
\hline Number of rats & 8 & 10 & 9 & 10 & 10 \\
\hline $\begin{array}{l}\text { Days of leucocytic smear } \\
\text { in first ovulatory cycle } \\
\text { Days of leucocytic smear }\end{array}$ & $5 \cdot 8 \pm 2 \cdot 8$ & $3 \cdot 2 \pm 1 \cdot 4$ & $6 \cdot 0 \pm 3 \cdot 4$ & $6 \cdot 6 \pm 3 \cdot 7$ & $3 \cdot 7 \pm 2 \cdot 8$ \\
\hline $\begin{array}{c}\text { in second ovulatory cycle } \\
\text { No. of 4-day oestrous cycles }\end{array}$ & $7 \cdot 0 \pm 3 \cdot 2$ & $5 \cdot 3 \pm 3 \cdot 4$ & $5 \cdot 9 \pm 3 \cdot 8$ & $5 \cdot 2 \pm 3 \cdot 6$ & $5 \cdot 4 \pm 4 \cdot 0$ \\
\hline $\begin{array}{l}\text { (showing } 2 \text { days of leucocytic } \\
\text { smears) before death }\end{array}$ & $1.8 \pm 0.9$ & $3 \cdot 0 \pm 1 \cdot 1$ & $2 \cdot 2 \pm 0.4$ & $2 \cdot 4 \pm 0.5$ & $3 \cdot 0 \pm 1 \cdot 3$ \\
\hline
\end{tabular}



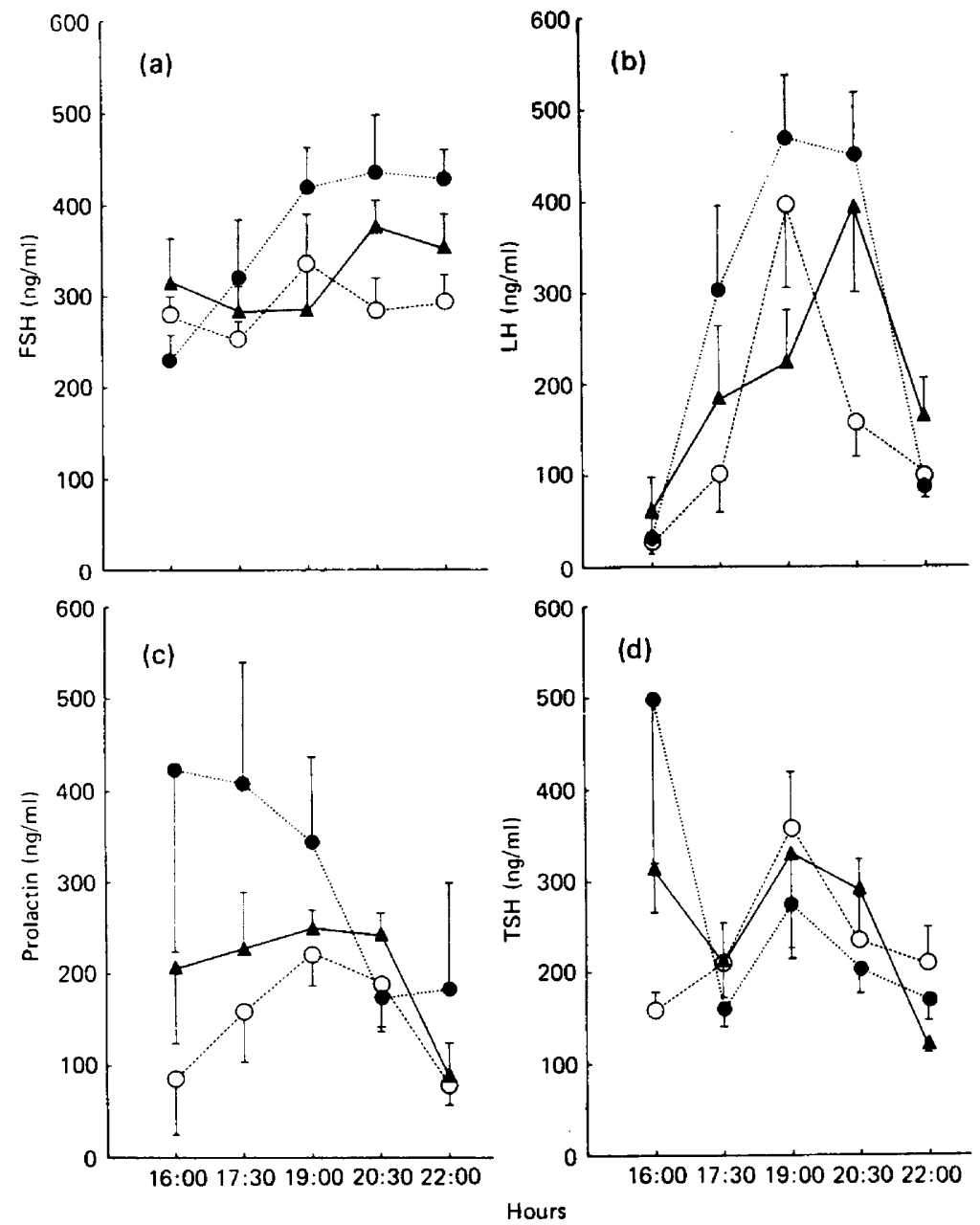

Text-fig. 1. Mean \pm s.e.m. plasma levels of (a) FSH, (b) LH, (c) prolactin, and (d) TSH for sham-operated rats $(\bullet)$, and rats with unilateral $(\Delta)$ or bilateral $(0)$ lesions of the preoptic area. There are at least 5 rats represented at each point.

The concentrations of all four hormones at the various times of sampling from the control animals were consistent with those previously reported for female rats during the afternoon of pro-oestrus (Brown-Grant et al., 1977). In the animals subjected to bilateral preoptic lesions, the initial phase of the preovulatory FSH secretion was lost (Text-fig. la): the values at 20:30 and 22:00 $\mathrm{h}$ were significantly lower than those in the control animals $(P<0.02$ and 0.005 respectively). Although peak levels of $\mathrm{LH}$ in the animals with bilateral lesions were not significantly different from those of controls (Text-fig. 1b), the values for 17:30 and 20:30 h were significantly lower $(P<0.01)$. Bilateral lesions therefore appear to have delayed the onset and hastened the offset of the preovulatory LH secretion without altering the peak concentration. However, the total amount of $\mathrm{LH}$ released was reduced : the ratio of the 'area under the curve' for $\mathrm{LH}$ release in controls, unilaterally lesioned and bilaterally lesioned rats was $1: 0 \cdot 67: 0 \cdot 46$. Prolactin concentrations in both groups of lesioned animals appeared reduced at 16:00 and 17:30 h (Text-fig. 1c). TSH values in the three groups did not differ (Text-fig. 1d), except at 16:00 $\mathrm{h}$ in animals with bilateral lesions, suggesting that damage to the preoptic area may have interfered with the normal circadian variation in plasma TSH concentrations (Brown-Grant et al., 1977) but not with the preovulatory rise of TSH. 


\section{Discussion}

There are two noteworthy features of the results presented in this paper. The first concerns the effect of the lesions on subsequent reproductive cycles, as assessed from vaginal cytology. In those rats with bilateral lesions the next two (and occasionally three) cycles were lengthened by additional days on which the vaginal epithelium contained large numbers of leucocytes. In some of the animals the period of dioestrus was approximately equal to that observed during pseudopregnancy (i.e. 12 days), although the average figure was about half as long. Although prolactin levels are elevated during these protracted dioestrous episodes, it is not yet possible to identify any correlations with the periods of prolonged dioestrus in the rats with the extensive preoptic lesions described by Clemens et al. (1976). Our experiments differ from theirs in that we destroyed less forebrain, and therefore, at the time of blood collection, nearly all of the rats represented in Text-fig. 1 had just shown at least 2 consecutive 4-day oestrous cycles. The more conservative approach in the present study is the probable explanation for the return to normal cycle lengths in the lesioned animals (see Table 2). This is able to occur even in the environment of an altered hormone profile on the afternoon of pro-oestrus, hence emphasizing the observation (Greig \& Weisz, 1973) that much of the preovulatory surges of hormones are secreted in excess of requirements for ovulation and maintenance of 4-day cyclicity.

The question arises as to the mechanism for the recovery of normal cycle length. A prolongation of the first post-operative cycle was to be anticipated since it is a familiar observation that any experimental manipulation may perturb the length of the following oestrous cycle. However, in the lesioned animals the second post-operative cycle was frequently the same length as the first (see Table 2), although there was a tendency for increased variability as shown by the larger standard deviations. Unusual hormone profiles may have influenced the second cycle length, and, although apparently similar, the early cycles may have differed significantly in, for example, the pattern of prolactin secretion. It is also possible that some reorganization of the surviving brain tissue may have taken place, perhaps also causing an increase in the numbers of receptors for positive feedback action of oestrogens. Studies to determine whether the hormone profiles changed progressively on each successive pro-oestrous afternoon after lesioning of the preoptic area would be of interest.

The second important feature of the results in this paper is the evidence that normal cyclic ovulation in the rat returns even though the preovulatory secretion of gonadotrophic hormones is significantly reduced from normal. The diminution of $\mathrm{LH}$ secretion is effected by reduction of duration rather than of the peak value. This observation is unlikely to be an artefact brought about in bilaterally lesioned rats by a change in the time of the 'critical period' because peak values were obtained at the same time in the controls. Furthermore, no high values were obtained for the experimental groups at $16: 00$ or $22: 00 \mathrm{~h}$, and the standard errors at these times were small.

The effects of unilateral lesions, destroying only about half the amount of preoptic tissue that the bilateral lesions did, were less marked: the hormone profiles were in general intermediate between those of the control and the bilaterally lesioned animals.

In conclusion, therefore, the results show that in female rats with regular ovulatory cycles the profiles of the normal preovulatory secretion of LH, FSH and prolactin are dependent, in part at least, upon the structural integrity of the preoptic area. In contrast, the preovulatory rise of TSH levels appears to be unaffected by small lesions in this area.

The work was supported in part by a grant from the M.R.C. to Dr K. Brown-Grant. D.S. is grateful to the Meat and Livestock Commission for a Summer Vacation Scholarship. We thank Linda Mayes and Sandra Mansfield for technical assistance, and Dr A. F. Parlow and the National Institute for Arthritis, Metabolism and Digestive Diseases, Rat Pituitary Program, for radioimmunoassay materials.

\section{References}

Brown-Grant, K. \& Greig, F. (1975) A comparison of changes in the peripheral plasma concentrations of luteinizing hormone and follicle-stimulating hormone in the rat. $J$. Endocr. 65, 389-397.
BROWN-GRANT, K. \& TER HAAR, M.B. (1977) Impairment of the control of gonadotrophin secretion after oestrogen administration to adult female rats. $J$. Endocr. 73, 497-505. 
Brown-Grant, K., Dutton, A. \& ter haAr, M.B. (1977) Variations in plasma thyrotrophin concentrations during the rat oestrous cycle. J. Endocr. 72, 33P-34P.

Clemens, J.A., Smalstig, E.P. \& Sawyer, B.D. (1976) Studies on the role of the preoptic area in the control of reproductive function in the rat. Endocrinology 99 , 728-735.
GoRSxi, R.A. (1966) Localisation and sexual differentiation of the nervous structures which regulate ovulation. J. Reprod. Fert., Suppl. 1, 67-88.

Greig, F. \& Weisz, J. (1973) Preovulatory levels of lutenizing hormone, the critical period and ovulation in rats. $J$. Endocr. 57, 235-245.

König, J.F.R. \& KLIPPEL, R.A. (1963) The Rat Brain. A Stereotaxic Atlas of the Forebrain and Lower Parts of the Brainstem. Williams \& Wilkins, Baltimore.

Received 21 September 1977 